\title{
Cryptogenic organising pneumonia: current understanding of an enigmatic lung disease
}

\author{
Ganesh Raghu ${ }^{1}$ and Keith C. Meyer ${ }^{2}$ \\ ${ }^{1}$ Dept of Medicine, Center for Interstitial Lung Diseases, University of Washington, Seattle, WA, USA. ${ }^{2}$ Dept of Medicine, University of \\ Wisconsin School of Medicine and Public Health, Madison, WI, USA.
}

Corresponding author: Ganesh Raghu (graghu@uw.edu)

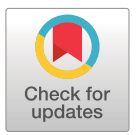

Copyright (T) The authors 2021

This version is distributed under the terms of the Creative Commons Attribution NonCommercial Licence 4.0. For commercial reproduction rights and permissions contact permissions@ersnet.org

Received: 11 April 2021 Accepted: 5 June 2021

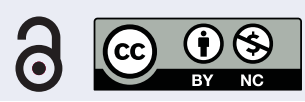

Shareable abstract (@ERSpublications)

The diagnosis of cryptogenic organising pneumonia requires the clinician to be prudent in eliminating several clinical conditions including: environmental factors, medications, systematic disease, aspiration pneumonia and infection, including COVID-19 https://bit.ly/3vf9NVm

Cite this article as: Raghu G, Meyer KC. Cryptogenic organising pneumonia: current understanding of an enigmatic lung disease. Eur Respir Rev 2021; 30: 210094 [DOI: 10.1183/16000617.0094-2021].

\section{Abstract}

Organising pneumonia (OP) is currently recognised as a nonspecific lung injury response that is associated with a variety of imaging patterns obtained with high-resolution computed tomography (HRCT) of the chest and is characterised histopathologically by the presence of inflammatory cells and a connective tissue matrix within distal airspaces of the lungs. OP is associated with many conditions that include connective tissue disorders, various infections, drug reactions, hypersensitivity pneumonitis and aspiration. When OP cannot be linked to an associated condition and appears to be idiopathic, it is termed cryptogenic organising pneumonia.

\section{Introduction}

\section{Historical aspects and terminology: from BOOP to COP}

Descriptions of organising pneumonia (OP) first appeared in medical literature from the late 1800s and early 1900s [1-3], and a detailed histopathological description was published in the early 20th century when autopsy specimens from patients who succumbed to nonresolving bacterial pneumonia were examined [2]. Over the course of the 20th century it was gradually recognised that OP could be seen in other conditions including connective tissue disease (CTD) and drug-induced pneumopathy. However, confusion regarding nomenclature and classification set in as idiopathic cases with features of interstitial lung disease (ILD) were described in the literature and different terminologies were coined.

An alveolar disease was described by DAvison et al. [4] and termed cryptogenic organising pneumonia (COP), while an airway disorder was described by GEDDEs and colleagues [5] and termed obliterative bronchiolitis (OB). LIEBOw and CARrington [6] described the same histopathologic pattern as Davison et al. [4] and used the term, bronchiolitis interstitial pneumonia (BIP). EpLER et al. [7] reviewed 2000 surgical lung biopsy reports and found 94 that mentioned the term bronchiolitis obliterans; 50 of these cases were idiopathic and showed a dominant histopathologic pattern of OP. However, EpLER et al. [7] coined the term, bronchiolitis obliterans organising pneumonia (BOOP) for their cases, although the lesions were essentially the same as those described previously by DAvison et al. [4] and changes of bronchiolitis obliterans in their cases were minimal. In the years following the report by EpLER et al. [7], BOOP became a "popular" term but was often confused with the separate and unrelated entity of bronchiolitis obliterans. However, the term COP better reflects the clinical and radiologic characteristics of the acinar-centric disorder of bronchopulmonary segments rather than the pathologic changes confined to the airways that are most consistent with an "airway disease". Indeed, bronchiolitis obliterans is primarily an obstructive airways disease that occurs without involving the parenchyma distal to airways. While bronchiolitis obliterans often occurs in recipients of lung, combined heart-lung, bone marrow and stem cell transplants as bronchiolitis obliterans syndrome, and in connective tissue diseases and inhalation injury, the cause may be unknown in some patients. Regardless, it is typically unresponsive to therapy and has a 
radically different appearance on HRCT to OP. While imaging of bronchiolitis obliterans reveals mosaic attenuation and bronchiectasis on HRCT, imaging of OP typically shows air space consolidation. Furthermore, OP has restrictive physiology and is generally responsive to corticosteroids and immunomodulatory therapy. The term, BOOP, which appears to combine two disorders with diametrically opposite features, led to a considerable degree of confusion concerning the entity of bronchiolitis obliterans versus the entity of $\mathrm{OP}$ and thus is currently seldom used.

CoRDIER et al. [8] examined a series of 16 patients and confirmed the predominance of an alveolar distribution of connective tissue buds and associated inflammatory changes. As various forms of idiopathic interstitial pneumonia (IIP) were differentiated on the basis of clinical, radiological and histopathologic characteristics throughout the 1990s, the term COP was retained for OP that could not be linked to a specific cause, and COP is currently classified as one of the major forms of IIP [9, 10]. This review will focus on what is currently recognised as COP. Most experts agree that the term, BOOP, should be discarded, although it still appears in the medical literature.

\section{Epidemiology and clinical features}

The incidence and prevalence of COP remain somewhat obscure, but a number of investigations in different populations indicate that disease onset usually occurs in the fifth to sixth decade of life (although it has been described in children), that there is no predilection for gender or race, that nonsmokers may have increased risk, and that annual incidence is approximately 1 per 100000 population [8, 11-20]. However, many cohorts reported in the literature were relatively small and included cases of OP linked to a specific aetiology. These cases are frequently termed secondary OP (table 1), which must be differentiated from COP $[19,20]$.

COP typically presents with features of community-acquired pneumonia or a flu-like illness with symptom onset usually $<2$ months prior to diagnosis. The most common presenting symptom in the majority of patients is a persistent, nonproductive cough that is variably accompanied by fever, fatigue, malaise, weight loss, and/or dyspnoea on exertion in half to two-thirds of patients [19-21]. However, COP may present in a small subset of patients as a rapidly progressive disorder that leads to acute respiratory failure that can meet criteria for acute respiratory distress syndrome (ARDS) [22, 23].

\section{TABLE 1 Conditions associated with organising pneumonia (OP)}

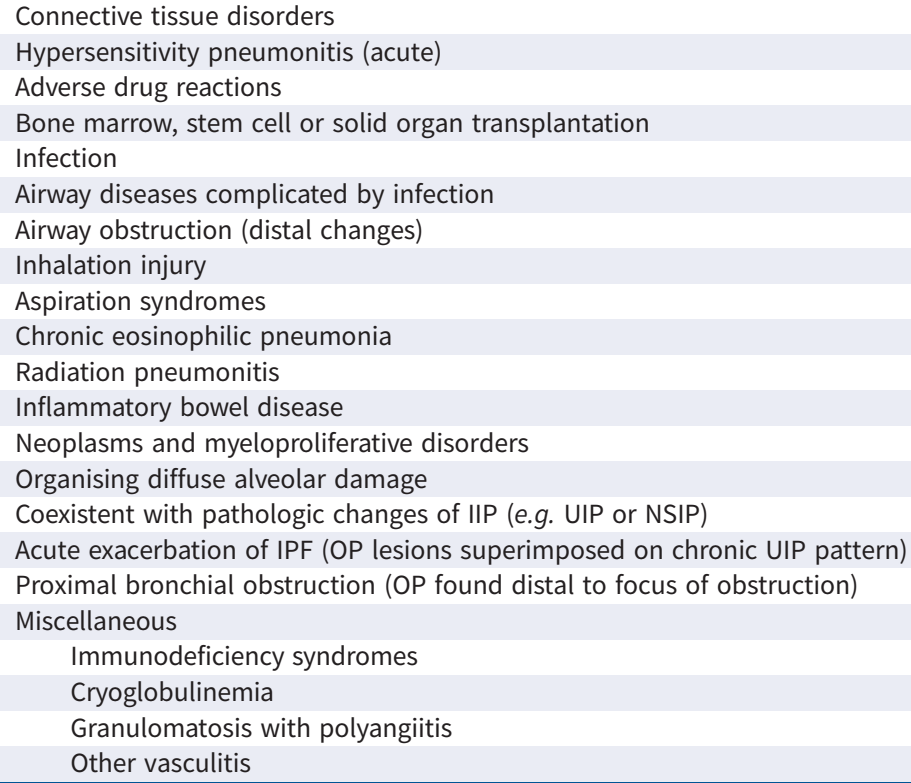

IIP: idiopathic interstitial pneumonia; UIP: usual interstitial pneumonia; NSIP: nonspecific interstitial pneumonia; IPF: idiopathic pulmonary fibrosis. "\#: conditions other than cryptogenic organising pneumonia (idiopathic OP) that have been associated with histopathologic findings of OP in lung tissue specimens. 
Physical examination of the chest reveals inspiratory crackles in most patients, and wheezing is usually not present. However, chest auscultation may not reveal any abnormal breath sounds in some patients, and digital clubbing is rarely seen. Routine laboratory studies are typically nonspecific with peripheral blood leukocytosis seen in approximately half of patients, and C-reactive protein and/or the erythrocyte sedimentation rate are frequently elevated. Pulmonary function testing is usually abnormal and shows a restrictive ventilatory defect. Airflow obstruction is uncommon and usually found only in current or former smokers. Gas exchange abnormalities are typically present with a reduction in single breath diffusing capacity of the lung for carbon monoxide $\left(D_{\mathrm{LCO}}\right)$ in a majority of patients, and exercise-induced hypoxaemia is commonly present.

\section{Pathogenesis and histopathology}

Alveolar epithelial injury with resultant epithelial cell death and disruption of the basal lamina is thought to represent the initiating event in COP $[9,24]$. Although the cause of COP is by definition unknown, one can speculate that possible aetiologies include occult viral infection, microaspiration of refluxed gastric secretions, or the presence of subclinical CTD. Although inflammatory cells (lymphocytes, neutrophils, some eosinophils) infiltrate the alveolar interstitium and plasma proteins and inflammatory cells leak into airspaces to form bands of fibrin that are associated with inflammatory cells, hyaline membrane formation as found in diffuse alveolar damage is not usually detected. These collections of fibrin and inflammatory cells along with fibroblasts that migrate from the interstitium to the airspaces and develop characteristics of myofibroblasts can then become organised to form fibro-inflammatory buds that gradually mature and form a connective tissue matrix that is prominently capillarised and relatively devoid of inflammatory cells. In contrast to usual interstitial pneumonia (UIP), the connective tissue matrix has a predominance of type III collagen (which is susceptible to degradation) but a relatively small amount of type I collagen [24].

This proliferation of granulation tissue buds (Masson bodies) (figure 1), which is found predominantly within airspaces (alveoli, alveolar ducts, and terminal bronchioles), represents the key histopathologic
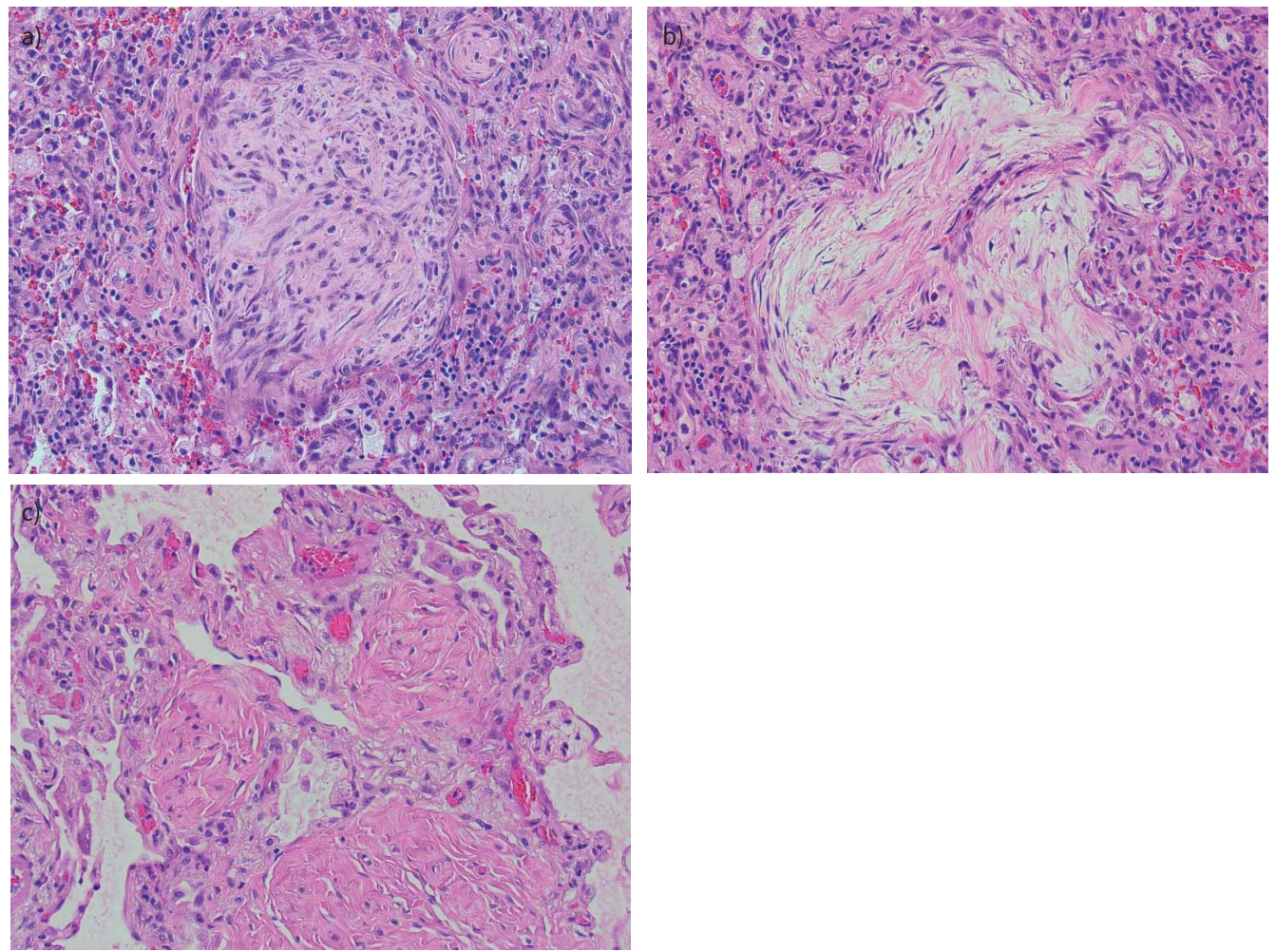

FIGURE 1 Histopathology of organising pneumonia. a) Typical Masson body (intraluminal plug of mucopolysaccharide-rich fibroblast proliferation without evidence of collagenous fibrosis). b) Masson body that is beginning to fibrose. Note pink strands of collagen starting to accumulate within the Masson body. c) Two Masson bodies that have undergone complete collagenous fibrosis and appear somewhat shrunken within the alveolar spaces. Photomicrographs provided courtesy of Scott Aesif (Dept of Pathology, Cleveland Clinic, Cleveland, OH, USA). 
feature of OP. Although some degree of interstitial inflammation is observed in surrounding tissue, the underlying lung architecture remains relatively preserved [9, 19, 24-26]. The lesions typically have a uniform temporal appearance, and advanced fibrotic changes are not usually present at the time of diagnosis, in contrast to the fibrotic changes of UIP. LAPPI-BLANCO et al. [27] have shown that apoptotic activity is high in the fibromyxoid connective tissue matrix of OP, and fibromyxoid lesions in OP are highly capillarised, a feature that characterises granulation tissue [28].

The injured lung is remodelled by re-epithelialisation and repair of basement membranes with resorption of matrix as lesions resolve spontaneously without therapeutic intervention or in response to treatment. Notably, although most patients who require treatment are corticosteroid responsive, Yousem et al. [29] reported that nearly all patients who have progressive disease despite such therapy had background scarring and remodelling of lung parenchyma in lung tissue specimens. Additionally, TonD et al. [30] reported a series of 38 patients who met the clinical-radiologic-histologic criteria for OP, of which 21 patients had histologic overlap of OP with coexistent changes of nonspecific interstitial pneumonia (NSIP). This OP/NSIP overlap cohort had significantly increased risk of disease progression.

\section{Radiographic imaging}

Bilateral and diffuse alveolar opacities with preserved lung volumes are the classic pattern seen on routine chest radiographs and HRCT imaging in patients with COP [31]. The opacities tend to be peripherally distributed, as is also seen in chronic eosinophilic pneumonia, and the opacities are often migratory and may spontaneously regress. Radiologic phenotypes reported by CoRDIER et al. [24] include subsegmental/ subpleural airspace consolidation in one lobe or one lung, bilateral subsegmental/subpleural airspace consolidation, bilateral changes consistent with fibrosis and subpleural airspace consolidation, and diffuse, rapidly progressive fulminant disease. The principal finding on HRCT of the chest is the presence of multifocal areas of airspace consolidation that are peripheral or peribronchial in distribution, have a predilection for the lung bases, and tend to change over a matter of weeks (figure 2) [31-33]. Air bronchograms can be observed in areas of consolidation, and ground-glass attenuation is seen in association with areas of consolidation in the majority of patients, but honeycombing is typically not present. Less frequently, diffuse infiltrative opacities that are peripheral and bilateral or a solitary mass or nodule can be seen. Additionally, a number of less common or unusual patterns (band-like, reversed halo, atoll or crazy paving) have also been described in association with OP but are nonspecific (table 2) [31].

As shown in figure $2(\mathrm{e}-\mathrm{h})$, the presence of multiple areas of consolidation that wax and wane or newly appear as consolidation develops in other lung regions should tip clinicians off that an immunologic/ inflammatory process is taking place and that a top diagnostic consideration is OP, although the differential diagnosis includes eosinophilic pneumonia or vasculitis.

\section{Diagnosis}

The diagnosis of COP should be suspected in patients who present with diagnosis-consistent clinical and radiological features (figure 3). A tissue biopsy with adequate sampling is considered by many experts to be essential for diagnosis. An adequate biopsy specimen allows other causes of OP (such as malignancy) to be ruled out and other forms of IIP to be differentiated from COP [10, 37]. Important and useful clues may often be obtained from HRCT imaging patterns, and bronchoscopic investigations can support a confident diagnosis without resorting to tissue sampling with surgical lung biopsy (SLB). If lesions migrate over time or areas of consolidation spontaneously regress, such findings help narrow the diagnostic differential to COP versus eosinophilic pneumonia, pulmonary vasculitis, or pulmonary haemorrhage [31]. Lymphocytes, plasma cells, and histiocytes are variably present within the interstitium in COP, and bronchoalveolar lavage (BAL) with a BAL differential cell count usually reveals a nonspecific inflammatory pattern with variable increases in lymphocytes, neutrophils, and/or eosinophils [38]. A lack of BAL eosinophilia lessens the likelihood of eosinophilic pneumonia as a diagnosis, and BAL analysis can be used to help rule out infection.

Although transbronchial biopsy (TBB) may retrieve diagnostic tissue, its diagnostic adequacy remains somewhat controversial. Polettr et al. [39] reported that in a series of 37 consecutive patients with suspected COP, of which 32 were subjected to TBB, sensitivity was $64 \%$, specificity $86 \%$, positive predictive value $94 \%$ and negative predictive value was $40 \%$. These investigators suggested that when patients are found to have a typical pattern of COP on HRCT combined with a compatible clinical presentation, evidence of COP on TBB, BAL findings supportive of COP and the absence of an underlying disorder that can cause secondary OP, a reasonably confident clinical diagnosis of COP can be made. CT-guided transthoracic needle biopsy has also been reported to have diagnostic accuracy that approaches that of SLB [33]. 

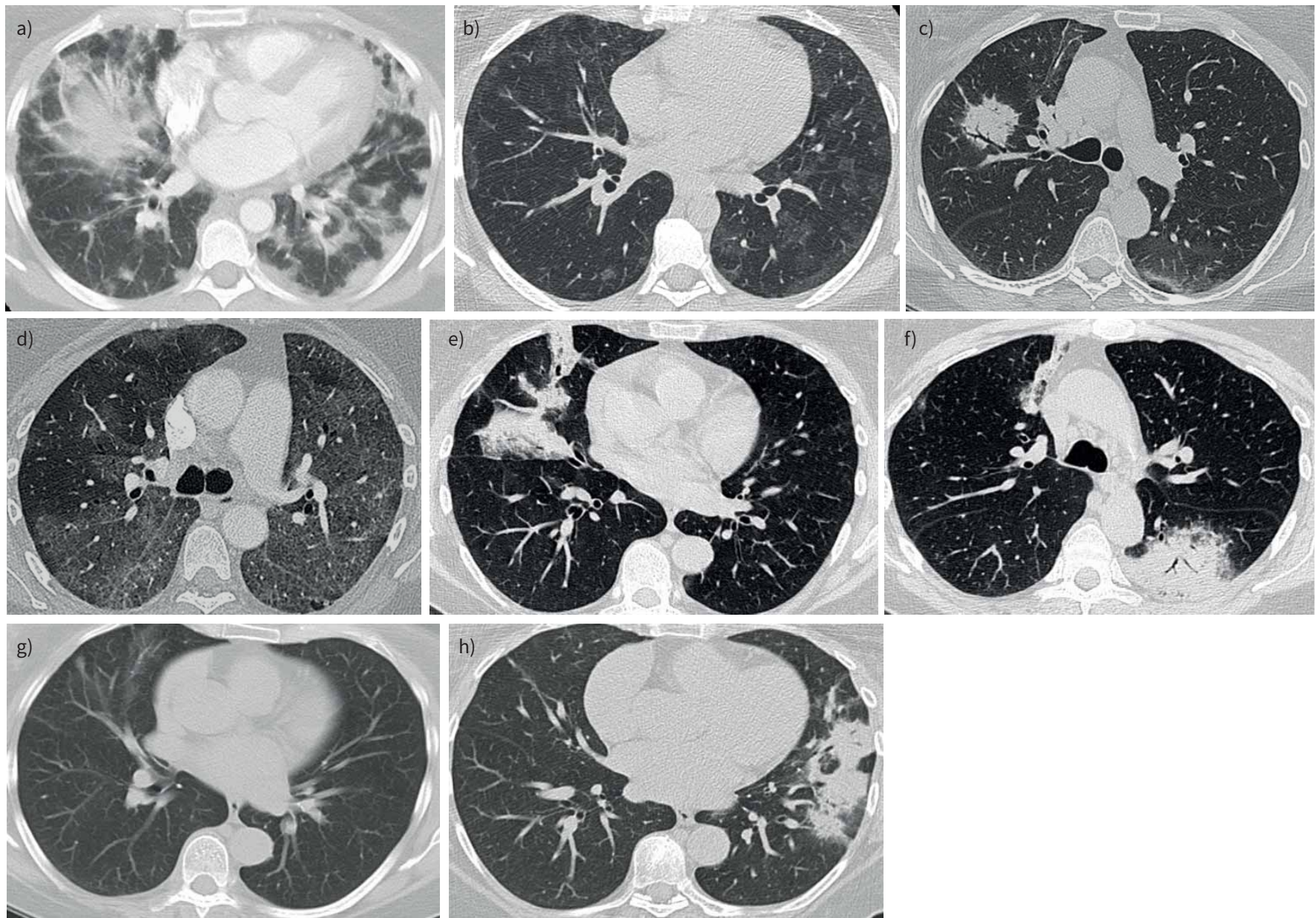

FIGURE 2 High-resolution computed tomographic imaging of organising pneumonia. a) Multiple areas of bilateral subpleural consolidation. b) Resolving lesions following 4 weeks of treatment with prednisone. c) Nodular consolidation with air-bronchogram. d) Ground-glass opacification. e and f) Multiple bilateral areas of nodular consolidation in a 58-year-old female (lung biopsy showed histopathologic changes of organising pneumonia. g) Near resolution following 2 months of corticosteroid therapy. h) Relapse with new lesions at 4 months following initial diagnosis despite treatment with $40 \mathrm{mg}$ of prednisone daily. The patient eventually improved with mycophenolate plus azithromycin and was gradually tapered off all drugs over 6 months following her second relapse (no recurrence was noted over 5 years of follow-up after all therapy was discontinued).

A pragmatic diagnostic approach (figure 3) that avoids resorting to performing a SLB could be particularly useful for patients for whom SLB entails an increased risk of serious complications, and transbronchial lung cryobiopsy (TBLC) could be considered by centres with adequate experience in this technique [40]. Additionally, COP should not be diagnosed solely on the basis of tissue histopathology, and a multidisciplinary approach to diagnosis is recommended [41]. Rapid clinical improvement with clearing of lung infiltrates on radiological imaging when treated with corticosteroids is also supportive of a diagnosis of COP, although eosinophilic pneumonia can also clear rapidly when patients are treated with corticosteroids. Of note, some patients who appear to have COP at initial diagnosis and have negative screening for clinical or laboratory findings indicative of an underlying CTD may subsequently develop such when followed over time [42].

Whether histologic confirmation of the presence of OP (via TBB, SLB or TBLC) is an ongoing debate, and data are lacking to support a need to retrieve lung tissue that confirms an OP diagnosis and rules out other potential diagnoses if the clinical presentation is consistent with a diagnosis of OP and a typical serial imaging profile is present. It is our opinion that SLB is rarely needed to secure a diagnosis unless the concern arises that other entities such as vasculitis need to be ruled out or the typical waxing/waning serial imaging profile is lacking. A less invasive approach using bronchoscopy with BAL to rule out infection 
TABLE 2 Radiographic imaging patterns of organising pneumonia

\section{Consolidation}

Subpleural and/or peribronchial

Mid to lower lung zone predominance

Can be perilobular

Opacities may migrate, wax, wane or disappear

Spontaneous regression of consolidated areas may occur

Combination of bilateral subpleural consolidation and mid to lower zone predominance observed in majority of patients

Other patterns

Focal with single nodule or mass

Nodular (variable size, can be solitary or multiple)

Reversed halo sign (ground-glass opacity, surrounded by a crescent or ring of consolidated parenchyma)

Ground-glass opacities (usually bilateral, patchy, seen in up to $90 \%$ of patients with cryptic organising pneumonia)

Parenchymal bands (often associated with multifocal consolidations)

Perilobular (arcade-like or polygonal opacities that are poorly defined and border secondary pulmonary lobules)

Fibrotic

Reticular opacities with basilar predominance, architectural distortion and superimposed alveolar opacities

Honeycomb change, traction bronchiectasis

Rare changes

Diffuse micronodules (centrilobular or peribronchial)

Mediastinal lymph node enlargement

Pleural effusion

and demonstrate the presence of an inflammatory BAL cell profile that lacks extreme eosinophilia can provide adequate information that supports a diagnosis of COP in the right clinical setting

\section{Treatment and outcomes}

Two distinguishing features of COP are its often dramatic response to corticosteroids and its tendency to spontaneously remit in some patients without any pharmacologic intervention [12, 41, 43]. Although a small subset of patients with COP may have spontaneous resolution and not require any pharmacologic intervention, treatment with corticosteroids is considered the standard of care for patients with nonresolving or progressive COP. Clinical improvement usually occurs within days after the onset of corticosteroid therapy, and complete clinical recovery accompanied by normalisation of the chest radiograph and physiologic improvement occurs in the majority of patients [7, 8, 12-14, 19, 44, 45]. Radiologic infiltrates resolve fairly rapidly in treatment responders, and complete resolution can be observed after a 3-month period of treatment [44].

Although most patients respond to corticosteroids, dosage and duration of therapy have not been studied in a clinical trial setting. Complete remission is more likely to occur when chest imaging shows airspace opacification but less likely in patients with a reticulo-nodular pattern [31,46]. Additionally, relapse is a common complication, although unpredictable, as corticosteroid dosages are tapered or discontinued (table 3) [44, 45, 47-54]. However, relapses do not appear to have a major effect on morbidity or mortality, and extended periods of treatment to prevent relapse expose patients to an increased risk of suffering adverse effects of corticosteroids $[20,44]$. Should relapse occur while on higher doses of corticosteroid $(\geqslant 20$ mg prednisone per day) or $>18$ months following the initial onset of COP, one should reconsider the diagnosis and entertain the possibility of a causal agent such as an undiagnosed CTD, hypersensitivity pneumonitis or a drug reaction.

LAzor et al. [44] reported one or more relapses in 58\% of a 48-patient cohort with biopsy-proven COP (table 3), and 68\% of relapsing patients were still receiving treatment for their initial episode of COP when their first relapse occurred. To lessen the cumulative dose of corticosteroids and risk of treatment-related side-effects, 14 patients were give a standardised regimen of $0.75 \mathrm{mg} \cdot \mathrm{kg}^{-1} \cdot \mathrm{day}^{-1}$ prednisone for 4 weeks, $0.5 \mathrm{mg} \cdot \mathrm{kg}^{-1} \cdot \mathrm{day}^{-1}$ for 4 weeks, $20 \mathrm{mg} \cdot \mathrm{day}^{-1}$ for 4 weeks, $10 \mathrm{mg} \cdot \mathrm{day}^{-1}$ for 6 weeks, and finally $5 \mathrm{mg} \cdot$ day $^{-1}$ for 6 weeks. Retrospectively assessed outcomes did not differ for patients given the standardised protocol versus patients given other regimens, but cumulative prednisone doses were reduced two-fold by using the suggested standardised protocol.

Intravenous corticosteroid boluses and other agents (cyclophosphamide, azathioprine, cyclosporine A) have been used for severe disease, but the efficacy of such approaches has not been established via clinical trial 
Patient with unexplained dyspnoea and/or cough and parenchymal infiltrates

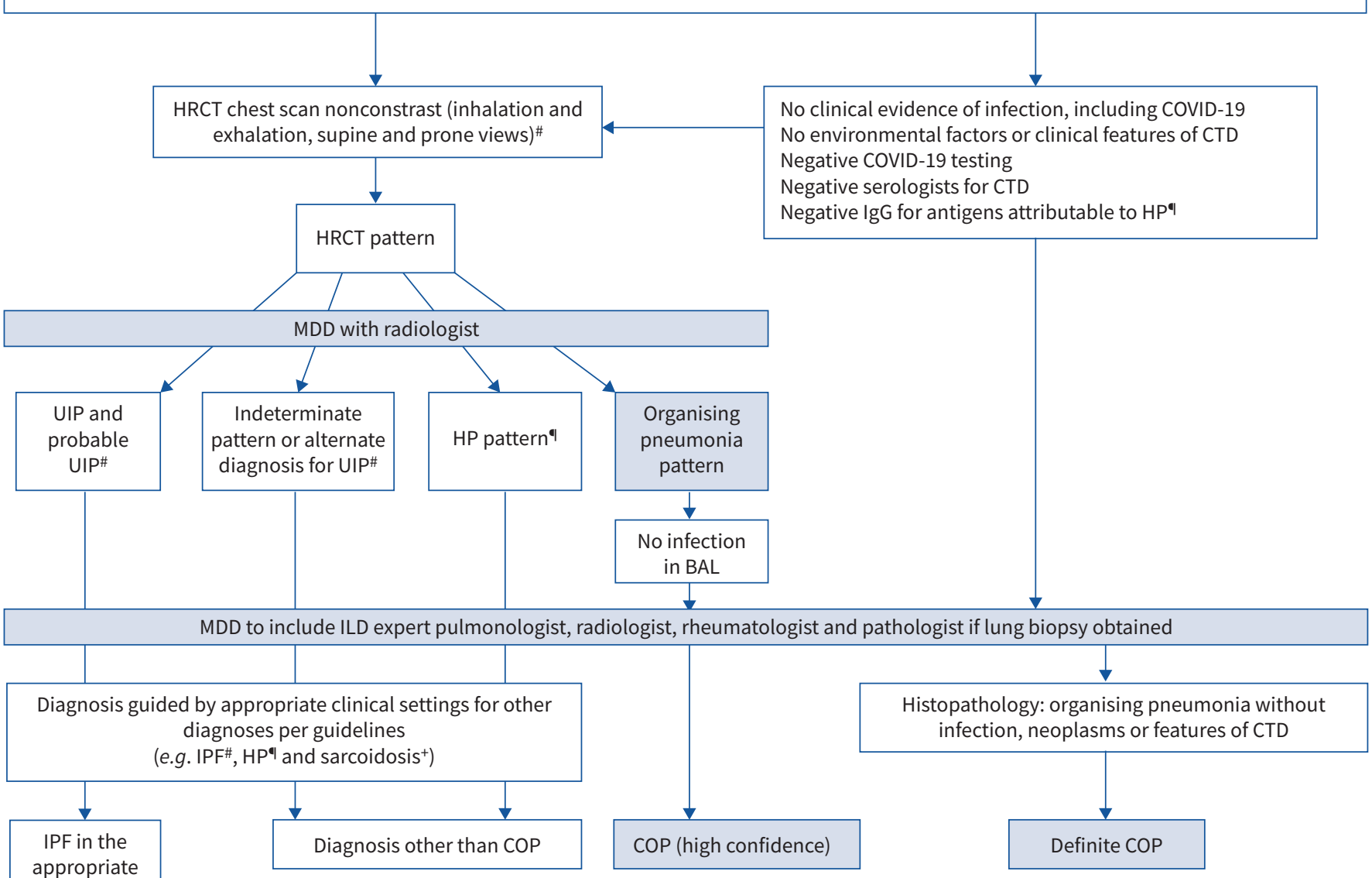

clinical setting

FIGURE 3 Diagnostic algorithm for the diagnosis of cryptogenic organising pneumonia (COP). BAL: bronchoalveolar lavage; COVID-19: coronavirus disease 2019; CTD: connective tissue disease; HP: hypersensitivity pneumonitis; HRCT: high-resolution computed tomography; Ig: immunoglobulin; ILD: interstitial lung disease; IPF: idiopathic pulmonary fibrosis; MDD: multidisciplinary discussion; UIP: usual interstitial pneumonitis. \#: RAGHU [34]; ๆ: RAGHu [35]; ${ }^{+}$: CROUSER [36].

settings. Macrolide antibiotics with 14- and 15-member ring structures (erythromycin, clarithromycin, and azithromycin) and anti-inflammatory properties have been used in uncontrolled settings with reports of some success in treating patients with mild COP [55-59]. Although it has been suggested that macrolides may be useful as an adjunctive therapy in combination with corticosteroids or other agents for more aggressive or relapsing disease [58, 60,61], whether there is a specific role for macrolides in treating COP remains unclear.

A small subset of patients may have changes consistent with interstitial fibrosis or a progressive fibrotic pattern on HRCT with basal reticulation and architectural distortion, and these findings correlate with a poorer prognosis [46]. CoHEN et al. [62] described a cohort of 10 patients diagnosed with BOOP who succumbed to progressive disease; six of 10 autopsy specimens showed predominant alveolar septal inflammation and fibrotic honeycombing. However, the majority of these patients had exposure to drugs or environmental agents or had a CTD associated with OP. The possibility exists that cases of progressive fibrotic disease may actually have underlying fibrosing NSIP or UIP with coexistent areas of pathologic change consistent with OP. The terms cicatricial and fibrosing organising pneumonia (FOP) have been applied to overlapping histology in patients with COP who may progress to pulmonary fibrosis [63, 64]. Nonetheless, while the possibility that some cases of COP may have a combined pattern of OP and interstitial fibrosis and/or transition over time to diffuse fibrotic disease with histologic characteristics of fibrotic NSIP, UIP, cicatricial and FOP and manifest progressive pulmonary fibrosis such that antifibrotic agents may potentially be beneficial, such a transition appear to be uncommon and has not been described in the medical literature to date. 
TABLE 3 Relapses in patients treated with corticosteroids

\begin{tabular}{|c|c|c|c|c|c|c|}
\hline First author [ref.] & $\begin{array}{c}\text { Patients } \\
\mathrm{n}^{\#}\end{array}$ & Number relapsed & $\begin{array}{l}\text { Length of } \\
\text { follow-up }\end{array}$ & Time to relapse & Fatal outcomes & Additional data \\
\hline LAZOR [44] & 48 & $\begin{array}{c}28(58 \%) \text { with } \geqslant 1 \text { relapse } \\
(68 \% \text { still under } \\
\text { treatment at } 1 \text { st relapse })\end{array}$ & $\begin{array}{c}35 \pm 31 \text { months } \\
\text { (median } 23 \text { ) }\end{array}$ & $\begin{array}{l}8 \pm 9 \text { months } \\
\text { (median 5; range } \\
2-46 \text { ) }\end{array}$ & $\begin{array}{l}\text { No deaths } \\
\text { attributable to COP or } \\
\text { relapse }\end{array}$ & $\begin{array}{l}9(19 \%) \text { with } \geqslant 3 \text { relapses } \\
\text { or Relapses beyond } 15 \text { months of first } \\
\text { relapse were rare }\end{array}$ \\
\hline LOHR [45] & 20 & $4(13 \%)$ & $\begin{array}{l}3.4 \text { years } \\
\text { (median) }\end{array}$ & NG & $\begin{array}{l}10 \text { out of } 37 \text { at } 10.5 \\
\text { years ( } 5 \text { pulmonary) }\end{array}$ & 5-year survival: $73 \%$ \\
\hline Zнои [47] & 73 & $23(31.5 \%)$ & $\begin{array}{l}\text { 50+27 months } \\
\text { (range 9- } \\
96 \text { months) }\end{array}$ & $\begin{array}{l}\leqslant 6 \text { months in } 8 \\
\text { of } 13 \text { following } \\
\text { CS cessation }\end{array}$ & None & $\begin{array}{c}\text { Fever, elevated C-reactive protein } \\
\text { and worse } D_{\text {Lco }} \text { associated with } \\
\text { relapse }\end{array}$ \\
\hline BARROSO [48] & 33 & $\begin{array}{l}18(56 \%) \text { out of } 32 \\
\text { responding to CS (all } \\
\text { responded to additional } \\
\text { therapy) }\end{array}$ & $54 \pm 40$ months & $\begin{array}{c}<6 \text { months in } 8 \\
\quad(44 \%) \\
\leqslant 1 \text { year in } 14 \\
\quad(78 \%) \\
\text { Mean time to first } \\
\text { relapse: } 10 \pm 12 \\
\text { months } \\
\text { (range } 2-54)\end{array}$ & $\begin{array}{l}7 \text { (none due to COP } \\
\text { recurrence; infection } \\
\text { in } 1 \text { ) }\end{array}$ & $\begin{array}{l}\text { Multifocal opacities predicted } \\
\text { relapse } \\
\text { Shortened CS maintenance (or lower } \\
\text { dose) associated with relapse } \\
\text { More rapid CXR normalisation when } \\
\text { treated for relapse }\end{array}$ \\
\hline ZHANG [50] & 53 & $35(70 \%)$ & NG & NG & 3 patients & $\begin{array}{c}50 \text { patients treated with CS } \\
\text { Relapsers responded to increased CS } \\
98.3 \% 5 \text {-year survival }\end{array}$ \\
\hline DRAKOPANAGIOTAKIS [51] & 40 & $\begin{array}{c}13(43 \%) \text { out of } 30 \text { within } \\
1 \text { year }\end{array}$ & NG & NG & $\begin{array}{c}\text { 1-year mortality: } 2 \\
(5.3 \%)\end{array}$ & In-hospital mortality $5.7 \%$ \\
\hline ONISHI [52] & 40 & $15(38 \%)$ & NG & NG & NG & $\begin{array}{c}\text { BAL neutrophilia and high levels of } \\
\text { tissue fibrin deposits correlated with } \\
\text { relapse }\end{array}$ \\
\hline SAITO [53] & 33 & $10(30.3 \%)$ & NG & $\begin{array}{l}476 \pm 445 \text { days } \\
\text { (range } 17- \\
682 \text { days) }\end{array}$ & NG & $\begin{array}{l}\text { Bilateral shadowing and traction } \\
\text { bronchiectasis predictive of relapse }\end{array}$ \\
\hline NISHINO [54] & 14 & $7(50 \%)$ & $\begin{array}{l}42(5-84) \\
\text { months }\end{array}$ & NG & NG & $\begin{array}{c}\text { Relapse associated with multifocal } \\
\text { intra-alveolar fibrin deposits and } \\
\text { more extensive involvement on chest } \\
\text { imaging }\end{array}$ \\
\hline
\end{tabular}

COP: cryptogenic organising pneumonia; NG: not given in manuscript; CS: corticosteroids; $D_{\text {Lco: }}$ diffusing capacity of the lung for carbon monoxide; CXR: chest radiograph; BAL: bronchoalveolar lavage. ": patients with COP treated with CS.

Conclusions and future directions

The use of two different terms, COP and BOOP, to describe the same entity in the medical literature led to considerable confusion when these entities were first described. Although the term BOOP has significance from a historical perspective, it is no longer used in current clinical practice or in newly published medical literature (and should not be used). The term COP should be exclusively used for the entity of OP of unknown aetiology.

With the evolving knowledge concerning the COVID-19 pandemic and the observation that radiographic manifestations are often similar to that of COP, it is now imperative to rule out COVID-19 in patients presenting with radiographic patterns of OP. In the absence of an identifiable association with a clinical condition such as infection, CTD, aspiration, hypersensitivity pneumonitis, drug reaction or other potential cause of OP, the diagnosis of COP can be ascertained with clinical and radiological features, although tissue sampling that shows histopathologic features of COP may occasionally be required. It has also become clear that many cases of COP described in older case series and case reports actually had secondary OP rather than a form of IIP that meets the current definition of COP. Every effort should be taken to rule out potential causes of OP before deciding that diagnostic criteria for COP have been met.

While COP can spontaneously remit without treatment, it usually responds rapidly to oral corticosteroid therapy and can completely remit with clearing of radiographic abnormalities, resolution of clinical symptoms and restoration of normal lung function. However, a significant number of patients will have relapses, although these will usually respond well to reinstitution or escalation of corticosteroid therapy. While a small subset of patients with COP may progress to persistent fibrotic lung disease, it is unknown 
whether such patients have a genetic predisposition to eventually manifest fibrotic changes that can mimic fibrotic NSIP or UIP. In addition, a small number of patients can present with acute disease and respiratory failure, and occasional patients can develop chronic and/or progressive disease that can lead to advanced lung disease with respiratory insufficiency. The genetic factors that are associated with treatment refractory or progressive fibrotic phenotypes need to be determined in future studies.

Provenance: Commissioned article, peer reviewed

Conflict of interest: G. Raghu reports personal fees and other funding from Boerhinger-Ingelheim and other funding from Roche-Genentech, outside the submitted work. K.C. Meyer has nothing to disclose.

\section{References}

$1 \quad$ Charcot JM. Des pneumonies chroniques. Rev Mensuelle Med Chir 1878; 2: 776-790.

2 Lange W. Über eine eigenthümliche Erkrankung der kleinen Bronchien und Bronchiolen (Bronchitis et Bronchiolitis obliter ns). Dtsch Arch Klin Med 1901; 79: 342-364.

3 Tripier R. Traité d'anatomie pathologique general. Paris, Masson, 1904.

4 Davison AG, Heard BE, McAllister WA, et al. Cryptogenic organizing pneumonitis. Q J Med 1983; 52: 382-394.

5 Geddes DM, Corrin B, Brewerton DA, et al. Progressive airway obliteration in adults and its association with rheumatoid disease. Q J Med 1977; 46: 427-444.

6 Liebow AA, Carrington CB. The interstitial pneumonias. In: Simon M, Potchen EJ, LeMay M, eds. Frontiers of Pulmonary Radiology. New York, Grune and Stratton, 1969; pp, 102-141.

7 Epler GR, Colby TV, McLoud TC, et al. Bronchiolitis obliterans organizing pneumonia. N Engl J Med 1985; 312: 152-158.

8 Cordier JF, Loire R, Brune J. Idiopathic bronchiolitis obliterans organizing pneumonia. Definition of characteristic clinical profiles in a series of 16 patients. Chest 1989; 96: 999-1004.

9 American Thoracic Society, European Respiratory Society. American Thoracic Society/European Respiratory Society International Multidisciplinary Consensus Classification of the Idiopathic Interstitial Pneumonias. This joint statement of the American Thoracic Society (ATS) and the European Respiratory Society (ERS) was adopted by the ATS board of directors, June 2001 and by the ERS Executive Committee, June 2001. Am J Respir Crit Care Med 2002; 165: 277-304.

10 Travis WD, Costabel U, Hansell DM, et al. An official American Thoracic Society/European Respiratory Society statement: update of the international multidisciplinary classification of the idiopathic interstitial pneumonias. Am J Respir Crit Care Med 2013; 188: 733-748.

11 Epler GR. Bronchiolitis obliterans organizing pneumonia: definition and clinical features. Chest 1992; 102: $2 \mathrm{~S}-6 \mathrm{~S}$.

12 Izumi T, Kitaichi M, Nishimura K, et al. Bronchiolitis obliterans organizing pneumonia. Clinical features and differential diagnosis. Chest 1992; 102: 715-719.

13 King TE Jr, Mortenson RL. Cryptogenic organizing pneumonitis. The North American experience. Chest 1992; 102: $8 \mathrm{~S}-13 \mathrm{~S}$.

14 Alasaly K, Muller N, Ostrow DN, et al. Cryptogenic organizing pneumonia. A report of 25 cases and a review of the literature. Medicine (Baltimore) 1995; 74: 201-211.

15 Inoue T, Toyoshima K, Kikui M. Idiopathic bronchiolitis obliterans organizing pneumonia (idiopathic BOOP) in childhood. Pediatr Pulmonol 1996; 22: 67-72.

16 Cazzato S, Zompatori M, Baruzzi G, et al. Bronchiolitis obliterans-organizing pneumonia: an Italian experience. Respir Med 2000; 94: 702-708.

17 Oymak FS, Demirbaş HM, Mavili E, et al. Bronchiolitis obliterans organizing pneumonia. Clinical and roentgenological features in 26 cases. Respiration 2005; 72: 254-262.

18 Gudmundsson G, Sveinsson O, Isaksson HJ, et al. Epidemiology of organising pneumonia in Iceland. Thorax 2006; 61: 805-808.

19 King TE Jr. Organizing pneumonia. In: Schwartz MI, King TE, Jr, eds. Interstitial Lung Disease. 5th Edn. Shelton, People's Medical Publishing House, 2011; pp. 981-994.

20 Cordier J, Cottin V, Lazor R, et al. Many faces of bronchiolitis and organizing pneumonia. Semin Respir Crit Care Med 2016; 37: 421-440.

21 Sveinsson OA, Isaksson HJ, Sigvaldason A, et al. Clinical features in secondary and cryptogenic organising pneumonia. Int J Tuberc Lung Dis 2007; 11: 689-694.

22 Nizami IY, Kissner DG, Visscher DW, et al. Idiopathic bronchiolitis obliterans with organizing pneumonia. An acute and life-threatening syndrome. Chest 1995; 108: 271-277.

23 Chang J, Han J, Kim DW, et al. Bronchiolitis obliterans organizing pneumonia: clinicopathologic review of a series of 45 Korean patients including rapidly progressive form. J Korean Med Sci 2002; 17: 179-186.

24 Cordier JF. Cryptogenic organising pneumonia. Eur Respir J 2006; 28: 422-446.

25 Colby TV. Pathologic aspects of bronchiolitis obliterans organizing pneumonia. Chest 1992; 102: 38S-43S. 
26 Myers JL, Colby TV. Pathologic manifestations of bronchiolitis, constrictive bronchiolitis, cryptogenic organizing pneumonia, and diffuse panbronchiolitis. Clin Chest Med 1993; 14: 611-622.

27 Lappi-Blanco E, Soini Y, Paakko P. Apoptotic activity is increased in the newly formed fibromyxoid connective tissue in bronchiolitis obliterans organizing pneumonia. Lung 1999; 177: 367-376.

28 Lappi-Blanco E, Kaarteenaho-Wiik R, Soini Y, et al. Intraluminal fibromyxoid lesions in bronchiolitis obliterans organizing pneumonia are highly capillarized. Hum Pathol 1999; 30: 1192-1196.

29 Yousem SA, Lohr RH, Colby TV. Idiopathic bronchiolitis obliterans organizing pneumonia/cryptogenic organizing pneumonia with unfavorable outcome: pathologic predictors. Mod Pathol 1997; 10: 864-871.

30 Todd NW, Marciniak ET, Sachdeva A, et al. Organizing pneumonia/non-specific interstitial pneumonia overlap is associated with unfavorable lung disease progression. Respir Med 2015; 109: 1460-1468.

31 Roberton BJ, Hansell DM. Organizing pneumonia: a kaleidoscope of concepts and morphologies. Eur Radiol 2011; 21: 2244-2254.

32 Faria IM, Zanetti G, Barreto MM, et al. Organizing pneumonia: chest HRCT findings. J Bras Pneumol 2015; 41: 231-237.

33 Miao L, Wang Y, Li Y, et al. Lesion with morphologic feature of organizing pneumonia (OP) in CT-guided lung biopsy samples for diagnosis of bronchiolitis obliterans organizing pneumonia (BOOP): a retrospective study of 134 cases in a single center. J Thorac Dis 2014; 6: 1251-1260.

34 Raghu G, Remy-Jardin M, Myers JL, et al. Diagnosis of idiopathic pulmonary fibrosis. An official ATS/ERS/JRS/ ALAT clinical practice guideline. Am J Respir Crit Care Med 2018; 198: e44-e68.

35 Raghu G, Remy-Jardin M, Ryerson CJ, et al. Diagnosis of hypersensitivity pneumonitis in adults. An official ATS/JRS/ALAT clinical practice guideline. Am J Respir Crit Care Med 2020; 202: e36-e69.

36 Crouser CD, Maier LA, Wilson KC, et al. Diagnosis and detection of sarcoidosis. An official American Thoracic Society clinical practice guideline. Am J Respir Crit Care Med 2020; 201: e26-e51.

37 Raghu G, Collard HR, Egan JJ, et al. An official ATS/ERS/JRS/ALAT statement: idiopathic pulmonary fibrosis: evidence-based guidelines for diagnosis and management. Am J Respir Crit Care Med 2011; 183: 788-824.

38 Meyer KC, Raghu G, Baughman RP, et al. An official American Thoracic Society clinical practice guideline: the clinical utility of bronchoalveolar lavage cellular analysis in interstitial lung disease. Am J Respir Crit Care Med 2012; 185: 1004-1014.

39 Poletti V, Cazzato S, Minicuci N, et al. The diagnostic value of bronchoalveolar lavage and transbronchial lung biopsy in cryptogenic organizing pneumonia. Eur Respir J 1996; 9: 2513-2516.

40 Ravaglia C, Wells AU, Tomassetti S, et al. Diagnostic yield and risk/benefit analysis of trans-bronchial lung cryobiopsy in diffuse parenchymal lung diseases: a large cohort of 699 patients. BMC Pulm Med 2019; 19: 16.

41 Bradley B, Branley HM, Egan JJ, et al. Interstitial lung disease guideline: the British Thoracic Society in collaboration with the Thoracic Society of Australia and New Zealand and the Irish Thoracic Society. Thorax 2008; 63: Suppl. 5, 1-58.

42 Henriet AC, Diot E, Marchand-Adam S, et al. Organising pneumonia can be the inaugural manifestation in connective tissue diseases, including Sjogren's syndrome. Eur Respir Rev 2010; 19: 161-163.

43 Guerry-Force ML, Müller NL, Wright JL, et al. A comparison of bronchiolitis obliterans with organizing pneumonia, usual interstitial pneumonia, and small airways disease. Am Rev Respir Dis 1987; 135: 705-712.

44 Lazor R, Vandevenne A, Pelletier A, et al. Characteristics of relapses in a series of 48 patients. The Groupe d'Etudes et de Recherche sur les Maladles 'Orphelines' Pulmonaires (GERM'O'P). Am J Respir Crit Care Med 2000; 162: 571-577.

45 Lohr RH, Boland BJ, Douglas WW, et al. Organizing pneumonia. Features and prognosis of cryptogenic, secondary, and focal variants. Arch Intern Med 1997; 157: 1323-1329.

46 Ujita M, Renzoni EA, Veeraraghavan S, et al. Organizing pneumonia: perilobular pattern at thin-section CT. Radiology 2004; 232: 757-761.

47 Zhou Y, Wang L, Huang M, et al. A long-term retrospective study of patients with biopsy-proven cryptogenic organizing pneumonia. Chron Respir Dis 2019; 16: 1479973119853829.

48 Barroso E, Hernandez L, Gil J, et al. Idiopathic organizing pneumonia: a relapsing disease. 19 years of experience in a hospital setting. Respiration 2007; 74: 624-631.

49 Yoo JW, Song JW, Jang SJ, et al. Comparison between cryptogenic organizing pneumonia and connective tissue disease-related organizing pneumonia. Rheumatology (Oxford) 2011; 50: 932-938.

50 Zhang Y, Li N, Li Q, et al. Analysis of the clinical characteristics of 176 patients with pathologically confirmed cryptogenic organizing pneumonia. Ann Transl Med 2020; 8: 763.

51 Drakopanagiotakis F, Paschalaki K, Abu-Hijleh M, et al. Cryptogenic and secondary organizing pneumonia: clinical presentation, radiographic findings, treatment response, and prognosis. Chest 2011; 139: 893-900.

52 Onishi $\mathrm{Y}$, Kawamura T, Nakahara $\mathrm{Y}$, et al. Factors associated with the relapse of cryptogenic and secondary organizing pneumonia. Respir Investig 2017; 55: 10-15.

53 Saito Z, Kaneko Y, Hasegawa T, et al. Predictive factors for relapse of cryptogenic organizing pneumonia. BMC Pulm Med 2019; 19: 10. 
54 Nishino M, Mathai SK, Schoenfeld D, et al. Clinicopathologic features associated with relapse in cryptogenic organizing pneumonia. Hum Pathol 2014; 45: 342-351.

55 Ichikawa $\mathrm{Y}$, Ninomiya $\mathrm{H}$, Katsuki $\mathrm{M}$, et al. Low-dose/long-term erythromycin for treatment of bronchiolitis obliterans organizing pneumonia (BOOP). Kurume Med J 1993; 40: 65-67.

56 Stover DE, Mangino D. Macrolides: a treatment alternative for bronchiolitis obliterans organizing pneumonia? Chest 2005; 128: 3611-3617.

57 Kastelik JA, Greenstone M, McGivern DV, et al. Cryptogenic organising pneumonia. Eur Respir J 2006; 28: 1291.

58 Ding QL, Lv D, Wang BJ, et al. Macrolide therapy in cryptogenic organizing pneumonia: a case report and literature review. Exp Ther Med 2015; 9: 829-834.

59 Radzikowska E, Wiatr E, Langfort R, et al. Cryptogenic organizing pneumonia - Results of treatment with clarithromycin versus corticosteroids - Observational study. PLoS One 2017; 12: e0184739.

60 Lee J, Cha SI, Park TI, et al. Adjunctive effects of cyclosporine and macrolide in rapidly progressive cryptogenic organizing pneumonia with no prompt response to steroid. Intern Med 2011; 50: 475-479.

61 Pathak V, Kuhn JM, Durham C, et al. Macrolide use leads to clinical and radiological improvement in patients with cryptogenic organizing pneumonia. Ann Am Thorac Soc 2014; 11: 87-91.

62 Cohen AJ, King TE Jr, Downey GP. Rapidly progressive bronchiolitis obliterans with organizing pneumonia. Am J Respir Crit Care Med 1994; 149: 1670-1675.

63 Beardsley B, Rassl D. Fibrosing organising pneumonia. J Clin Pathol 2013; 66: 875-881.

64 Yousem SA. Cicatricial variant of cryptogenic organizing pneumonia. Hum Pathol 2017; 64: 76-82. 